\title{
François René de CHATEAUBRIAND, CEuvres complètes
}

Sous la direction de Béatrice DIDIER, Paris, Honoré Champion, 2009, t. I-II en un volume, 1324 p., ISBN 978-2-7453-1737-7, $230 €$

\section{Michel Biard}

\section{OpenEdition \\ Journals}

\section{Édition électronique}

URL : https://journals.openedition.org/ahrf/11594

DOI : 10.4000/ahrf.11594

ISSN : 1952-403X

\section{Éditeur :}

Armand Colin, Société des études robespierristes

\section{Édition imprimée}

Date de publication : 1 octobre 2009

Pagination : 209-210

ISBN : 978-2-200-92560-4

ISSN : 0003-4436

\section{Référence électronique}

Michel Biard, «François René de chateaubriand, EEuvres complètes », Annales historiques de la Révolution française [En ligne], 358 | octobre-décembre 2009, mis en ligne le 29 juillet 2010, consulté le 23 avril 2022. URL : http://journals.openedition.org/ahrf/11594 ; DOI : https://doi.org/10.4000/ahrf.11594

Ce document a été généré automatiquement le 23 avril 2022.

Tous droits réservés 


\section{François René de CHATEAUBRIAND, Euvres complètes}

Sous la direction de Béatrice DIDIER, Paris, Honoré Champion, 2009, t. I-II en un volume, 1324 p., ISBN 978-2-7453-1737-7, $230 €$

\section{Michel Biard}

\section{RÉFÉRENCE}

François René de CHATEAUBRIAND, Euvres complètes, sous la direction de Béatrice DIDIER, Paris, Honoré Champion, 2009, t. I-II en un volume, 1324 p., ISBN 978-2-7453-1737-7, $230 €$

1 Aussi étrange que cela puisse paraître, nous ne disposions encore d'aucune édition des Euvres complètes de Chateaubriand. Les éditions du XIX ${ }^{\mathrm{e}}$ siècle sont lacunaires et, plus récemment, la prestigieuse collection La Pléiade n'a donné que certains ouvrages de l'auteur. Béatrice Didier et toute l'équipe rassemblée autour d'elle se sont donc lancé dans une entreprise de longue haleine accueillie par les Éditions Champion, toujours si précieuses sitôt qu'il s'agit de publier des textes essentiels qui appartiennent au patrimoine mondial de la littérature. Il fallait bien sûr trouver une édition de référence, en compléter les lacunes et élaborer un appareil critique susceptible, d'une part, de permettre la comparaison avec d'autres éditions de référence, d'autre part, d'éclairer au mieux les textes de l'auteur. Le choix s'est porté sur la publication réalisée par l'éditeur Ladvocat, avec lequel Chateaubriand passa contrat en 1826. La parution des 28 tomes, répartis en 32 volumes, s'étendit de cette année là à 1831. Cela va de soi, il convenait donc d'emblée de compléter la présente édition avec tout ce qui fut postérieur à 1831. Ladvocat publia les tomes dans un " désordre » choisi, la première livraison étant non l'Essai sur les révolutions, qui formait les tomes I et II, mais le tome XVI qui regroupait des œuvres jugées plus propices à séduire le public (Atala, René, Les Aventures du dernier Abencérage). Chez Honoré Champion, on retrouvera au contraire l'ordre initial des textes, à ceci près que le présent volume, s'il contient bien les tomes I 
et II de Ladvocat, s'ouvre, en bonne logique, par une présentation rédigée par Béatrice Didier et par la "préface générale » de Chateaubriand qui était alors placée dans le tome XVI. Cette édition scientifique donne toutes les variantes que les écrits de Chateaubriand ont connues au gré des éditions postérieures à 1826-1831, ainsi que de nombreuses et passionnantes "notes explicatives, historiques et littéraires». On y trouvera également des index des noms de personnes et de lieux, ainsi que des documents sur la genèse des textes et leur réception. Dans ce précieux volume d'une édition dont on attend désormais avec impatience les tomes suivants, le lecteur découvrira encore un tableau synoptique des parallèles entre les révolutions (bien utile tant sont parfois étranges les rapprochements) et une étude sur les sources utilisées par Chateaubriand. S'agissant de ce qu'il a employé pour la Révolution française, Le Moniteur et d'autres journaux, les textes de Peltier et Montjoie sont omniprésents, ce qui ne pouvait que lui offrir une vision partielle et partiale des événements. La liste de ses sources pour l'ensemble de l'Essai fait apparaitre une soixantaine de noms ou titres, mais il y en a eu sans doute davantage, nombre d'autres étant difficiles à déterminer (environ 250 ouvrages sont mentionnés par Chateaubriand dans ses notes).

2 L'Essai historique, politique et moral, sur les révolutions anciennes et modernes, considérées dans leurs rapports avec la révolution françoise, a été publié pour la première fois à Londres en 1797 et "dédié à tous les partis". Chateaubriand le confia à Ladvocat sans le modifier, mais en y ajoutant des notes, qui autorisent une sorte de « dialogue entre le Chateaubriand de la jeunesse et celui de la maturité ». Dans sa "préface générale » à l'ensemble de ses Euvres, il écrivait notamment : «Qu'il faille en gémir ou s'en féliciter, mes écrits ont teint de leur couleur grand nombre des écrits de mon temps; mon nom, depuis vingt-cinq années, se trouve mêlé aux mouvements de l'ordre social [...] Quand on a vu la révolution françoise, dites-vous, que peut-il survenir qui soit digne d'occuper les yeux ? La plus vieille monarchie du monde renversée, l'Europe tour à tour conquise et conquérante, des crimes inouïs, des malheurs affreux recouverts d'une gloire sans exemple : qu'y a-t-il après de pareils événements? Ce qu'il y a ? Portez vos regards au delà des mers. L'Amérique entière sort républicaine de cette révolution que vous prétendiez finie et remplace un étonnant spectacle par un spectacle plus étonnant encore ». Resterait à discuter semblable affirmation, qui contient en germes tout un débat historiographique postérieur, mais tel n'est pas le but de ce compte rendu.

3 L'Essai sur les révolutions, pour reprendre le titre plus court sous lequel il est en général connu, prend place dans les années d'émigration de Chateaubriand, entre le 21 mai 1793, date de son arrivée à Londres, et le 18 mars 1797, date de la publication. Le début de la rédaction est souvent situé en 1794 et son achèvement à la fin de 1796, pourtant il semble que l'essentiel en ait été rédigé en 1796 et la plus ancienne des références au Paris du journaliste contre-révolutionnaire Peltier date de la fin d'octobre 1795. La réception de l'Essai à sa parution ne fut pas à la hauteur des espoirs de son auteur. En Angleterre et dans les milieux de l'émigration, le texte, comme le dit lui-même Chateaubriand, entra «en contradiction avec les sentiments de [s]es compagnons d'infortune", car il proposait un modèle de monarchie constitutionnelle pouvant déplaire à plus d'un émigré. En France, le succès ne fut pas plus grand, y compris auprès de ses amis de La Décade philosophique. Cet accueil comme d'ailleurs celui plus tard réservé à l'édition Ladvocat rejoignent pour l'essentiel l'avis des critiques d'aujourd'hui : incongruité des parallèles entre les événements et les personnages de la Révolution française et du passé, désordre fréquent, barbarismes, etc.; aussi, «c'est 
finalement Chateaubriand qui a été le meilleur juge lui-même dans les Mémoires d'outretombe et qui a énoncé la définition le plus heureuse de l'Essai comme un "livre de doute et de douleur" ".

4 L'ouvrage se lit aujourd'hui avec intérêt pour peu que l'on se passionne pour la période révolutionnaire, même si le désordre et nombre de lourdeurs rendent une lecture continue assez peu agréable. Mieux vaut sans doute lire des passages çà et là, progresser, revenir en arrière, etc.; on serait presque tenter de dire "picorer ». À ce jeu, il est impensable d'en résumer ici le contenu en quelques lignes; d'aucuns s'indigneront devant des formules aussi assassines qu'infondées (les "Jacobins" massacrant les propriétaires, anéantissant le commerce aussi bien que les Lettres, mariant de force les jeunes "vierges", se préparant "à promulguer les lois agraires »...), d'autres se contenteront de la beauté de la langue et laisseront de côté les nombreuses erreurs factuelles ou les partis pris, d'autres encore s'arrêteront sur tel ou tel passage. Ainsi, comment ne pas ici faire état de ce que Chateaubriand écrit à propos de Robespierre au 9 Thermidor: "Mis hors de la loi par un décret de la Convention, déserté de toute la terre, il ne put même échapper à ses ennemis par ce moyen qui nous soustrait à la persécution des hommes, et la fortune le trahit jusqu'à lui refuser un suicide. Arraché par les gardes de derrière une table où il avoit voulu attenter à ses jours, il fut porté, baigné dans son sang, à la guillotine. Robespierre sans doute n'offroit par sa mort qu'une foible expiation de ses forfaits; mais quand un scélérat marche à l'échafaud, la pitié alors compte les souffrances, et non les crimes du coupable ».

5 Même si Chateaubriand ajoute en 1826 une note pour tenter d'excuser cette " pitié ", arguant de ce qu'il ne savait pas tout et qu'il a alors pris là " pour des personnages, de vulgaires factieux ", le passage n'en reste pas moins beau. 